\title{
Manuscripts, Memory and History: Classical Tamil Literature in Colonial India, by V. Rajesh
}

New Delhi: Cambridge University Press India, 2014 | 304 pages | ISBN: 978-9-382993-049 (hardcover) Rs. 895

\section{In Manuscripts, Memory and History: Classical Tamil} Literature in Colonial India, V. Rajesh traces the circulation, printing and reception of classical Tamil lit-

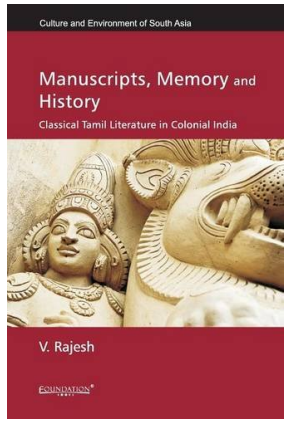
erature in nineteenth-century Madras Presidency. In his introductory chapter, Rajesh acknowledges the impossibility of capturing what he calls a narratable and unified history of classical Tamil literature. The book aims to redefine or expand an idea of literary history to include the cultural and economic conditions that produce articulations of the literary. While Rajesh concedes the fact that the Tamil literary field is fluid and discontinuous, the book still attempts to provide a unified history of the reproduction and reception of classical Tamil literature.

Chapter 2, "Interrogating 'Rediscovery' and an Enquiry into the Transmission of Sangam Literature during the Pre-modern Period," questions what twentieth-century Tamil historical scholarship has termed the "rediscovery" of the classical Sangam corpus. Rajesh explores sites of literary circulation that have not received scholarly attention-Jain mutts, missionary documents, the early colonial records of the Mackenzie collections, the Board's collections of the College of Fort St George, and colonial book productionto suggest that the Tamil classics were far from being rediscovered through print. The chapter tracks the pre-modern transmission, production, and compilation of the Sangam corpus and suggests that the idea of the Sangam as an academy of poets who produced the earliest Tamil poetry was embedded in the Tamil literary imagination. What the chapter also reveals is the lack of scholarly consensus on what constituted the Sangam corpus and when these poems were composed. The flexibility of the literary tradition is replicated in modern scholarly debates after the publication of classical Tamil literature.

Chapter 3, "Patrons and Networks of Patronage in the Publication of Tamil Classics," looks at networks of patronage that supported the publication of the Tamil classics in the nineteenth century. Rajesh identifies three phases in the history of Tamil print: firstly, the collection, editing, and printing of palm leaf manuscripts by pundits and students in the College of Fort St George; secondly, the editorial and printing activities of Aru- 
muga Navalar who spearheaded the Saiva revival movement in Jaffna; and thirdly, the editorial works of C. W. Damodaran Pillai and U. V. Saminatha Iyer among others. While modern historical scholarship has largely relied on Saminatha Iyer's autobiography and his edited works in their understanding of nineteenth-century literary culture, Rajesh draws out the continuities and discontinuities between three overlapping sites of literary production in the nineteenth century. The College of Fort St George mostly published Tamil grammars and dictionaries that as Rajesh argues, did not result in a new understanding of the Tamil literary past. It was Arumuga Navalar's publishing of various Saiva and non-Saiva texts and the editorial contributions of Damodaran Pillai and Saminatha Iyer that fueled twentieth-century debates on the antiquity of Tamil language and literature. Rajesh reveals the nexus between the wealthy landholding Saiva mutts of Thiruvavadathurai and Ramanathapuram that patronized the upper-caste pundits of the College of Fort St. George as well as Arumuga Navalar, Damodaran Pillai and Saminatha Iyer. Navalar's efforts to resist the spread of Protestantism were reflected in the publication of several Saiva and non-Saiva texts and their commentaries. A list of the books he published also included medieval commentaries on Sangam and post-Sangam literatures. Damodaran Pillai and Saminatha Iyer edited and published the Sangam anthologies along with their commentaries for the first time. Like other native pundits of the time, Pillai and Iyer's editorial efforts were not acknowledged by the colonial state that was more interested in sponsoring dictionaries and grammars to help its officials learn the language. Pillai and Iyer thus had to approach the Saiva mutts that had patronized Navalar or seek the interventions of non-native scholars like G. U. Pope to get state support. In this chapter Rajesh dismisses the popular view in modern scholarship that believed the Tamil classics were ignored because of religious sectarianism. Such a view, Rajesh argues, ignores the role of the Jain and Saiva mutts and the kavirayars or travelling poets in disseminating Tamil literature.

Chapter 4, "From Reproduction to Reception: The Writing of Literary Histories," notes the emergence of literary histories by native scholars that critiqued colonial philological scholarship. The publication of the Tamil classics enabled native scholars to push back the antiquity of Tamil literature to eight centuries earlier than what was widely assumed by European scholars. This had important implications for the rise of the Dravidian Non-Brahmin Movement in the early decades of the twentieth century.

Chapter 5, "Orientalism, Tamil Classics and the Organizational Politics," explores the political role that the publication of Tamil classics played 
in twentieth-century Madras Presidency. The advertizing of the newly published classics in vernacular and English newspapers and periodicals, the establishment of language promotion associations and the insertion of these classics in university curricula created a new literary consciousness among the literate public. The knowledge of these classics also helped an elite segment of the Non-Brahmin population to contest Brahmin dominance in the colonial public sphere. The political hostility against Brahmins was extended to the cultural sphere with the publication of the Tamil classics that were seen as emblematic of a Dravidian tradition untouched by Sanskrit and Brahminism. Brahmins were identified as custodians of an alien Aryan religious tradition who were out to destroy Dravidian culture. The binary opposition between Brahmin and Non-Brahmin, Aryan and Dravidian, and Sanskrit and Tamil were first laid out by the philological writings of Robert Caldwell in his comparative grammar of the Dravidian family of languages. The Tamil classics were repeatedly invoked by the Non-Brahmin Justice Party and nationalists to glorify the historical valor of Tamils in their fight against the colonial regime and Brahmin domination.

Unlike most Tamil literary historical scholarship, Rajesh's book provides a comprehensive history of the publishing and political reception of the Tamil classics. However, more attention could have been paid to the diegetic worlds of these texts. Although Rajesh claims to offer a history of Tamil literary cultures, the book does not give the reader an idea of the texts themselves and the commentarial traditions that formed the earliest instance of Tamil literary criticism. One way of addressing this concern would be to provide a glossary that familiarizes the reader with the major thematic and formal concerns of these texts and the shifting criteria by which they were interpreted and judged. This would also help the reader understand the politics of literary canon formation in terms of why certain texts or genres gained a certain prominence over others at particular historical junctures. It is thus not necessary or desirable, I believe, to promise a unified history of Tamil literature but acknowledge the productive continuities and discontinuities of an elastic literary field.

Although the introductory chapter suggests Rajesh's familiarity with the larger field of scholarship on print histories, a more critical engagement with these sources is necessary. What could have been addressed in this review of print scholarship is the significance of his book's intervention in the field.

What could also have been addressed in greater detail are the conditions under which palm leaf manuscripts were transcribed and published. It is not clear whether there were discrepancies in various manuscript copies of 
the same text that may have had implications in the way they were received and interpreted. In many instances the printing and standardization of these texts may have had to deal with inconsistencies that resulted in significant semantic shifts.

Another aspect that the book has only mentioned in passing is the contemporary literary culture of the nineteenth century and the ways in which these texts circulated and were read against the authoritative classics. It becomes important for this reason to delineate the circulations of classical and contemporary Tamil texts within the literary domains of the Jain and Saiva mutts. What was the nature of the religious and literary exchanges between these institutions? Were the different religious affiliations of these mutts reflected in the literary works they possessed and if so how? What were the social identities of the kavirayars and the nature of their associations with these mutts? This becomes significant when one considers the fraught history of inter-religious violence and conversions that characterized the sectarian exchanges between Saivism, Vaishnavism, Jainism, and Buddhism. It is thus important not to assume either Bhakti is a symbol or Jainism and Buddhism are symbols of religious tolerance or peace but as deeply fissured by sectarian and caste violence.

Kiran Keshavamurthy

Centre for Studies in Social Sciences, Kolkata 